\title{
Effects of shape and size of hybrid maize seed on germination and vigour of different genotypes
}

\author{
Marijenka Tabakovic $^{1^{*}}$, Milena Simic ${ }^{1}$, Rade Stanisavljevic ${ }^{2}$, Marija Milivojevic ${ }^{1}$, Mile Secanski ${ }^{1}$, \\ and Dobrivoj Postic ${ }^{2}$
}

${ }^{1}$ Maize Research Institute Zemun Polje, Slobodana Bajića 1, 11185 Belgrade-Zemun, Serbia.
*Corresponding author (mtabakovic@ @rizp.rs).
${ }^{2}$ Institute for Plant Protection and Environment, Teodora Drajzera 9, 11040 Belgrade, Serbia.

Received: 21 February 2020; Accepted: 12 May 2020; doi:10.4067/S0718-58392020000300381

\begin{abstract}
The uniform seed material is a prerequisite of stable yields. Therefore, the aim of the study was to observe variability of physiological seed traits depending on the classification of seeds by size and shape, and to determine advantages of large over small seed fractions. Three maize (Zea mays L.) hybrids (ZP 505, ZP 677, ZP 684), produced in two locations (Orahovo, Plavna), were classified into six fractions; small flat seed (SFS), medium small flat seed (MSFS), large flat seed (LFS), small round seed (SRS), medium small round seed (MSRS) and large round seed (LRS). Two laboratory treatments were applied on seed: TR 1 (cold test) and TR2 $\left(20 / 30^{\circ} \mathrm{C}\right)$. In both temperature treatments, the first evaluation was done after 72 -h germination, and then every $24 \mathrm{~h}$ until $7^{\text {th }}$ day. The highest total germination $(\mathrm{G})$ was recorded for $\mathrm{ZP}$ 677 (93.7\%), location Orahovo (94.9\%), temperature TR2 (95.2\%) and MSFS fraction (89.7\%). The total proportion of factors in the variance for $\mathrm{G}$ was $\mathrm{R}^{2}=0.694$. Locations and genotypes predominantly affected the germination rate (GR), $\eta=0.338$. Flat fraction seeds had more rapid emergence $(>90 \%)$ of seedlings than the round fraction seeds $(>85 \%)$. Round seeds were more susceptible and seed size had a greater effect on vigour than LRS, 70\%. The partial effect of the fraction on $\mathrm{G}$ was not estimated $(\eta=0.037)$, but its cumulative effect with other factors was evident (Hybrid $\times$ Fraction, $\eta=0.070)$.
\end{abstract}

Key words: Physiological traits, seed size, Zea mays.

\section{INTRODUCTION}

Stable yields depend on different moisture, structure and temperature of soil, plant residues, sowing method and seed quality (Pommel et al., 2002; Anders et al., 2020). The shape, size, weight, germination and vigour are physiological and morphological seed quality parameters. Seed germination according to the ISTA germination test (ISTA, 2019) is "the emergence and development of the seedling to a stage where the aspect of its essential structures indicates whether or not it is able to develop further into a satisfactory plant under favourable conditions in soil". The second seed quality parameter is vigour. It is defined as a set of seed traits determining the potential and activity level for the emergence and development of seedlings within a wide range of environmental conditions (ISTA, 2019). It is expected that the high-vigour seeds would emerge more uniformly even under germination conditions that were less than ideal (Egli and Rucker, 2012).

The properties of produced hybrid maize (Zea mays L.) seeds depend on many factors: genotypic combinations of parental inbreds, synchronicity of flowering, pollination period, grain filling period, maturation period, moisture content in physiologically mature seed at harvest, harvest seed maturity, diseases caused by phytopathogenic agents, presence of pests. Properties of seeds exposed to these factors change. Variability of agroecological conditions may alter the growth and 
development of maize (Bergamaschi et al., 2007; Asare et al., 2011; Chen et al., 2011; Rattalino Edreira et al., 2011; Zhou et al., 2016). Stress caused by drought, insufficient light, especially in the period from silking to full maturity, leads to the reduction in DM accumulation, which results in a smaller seed weight (Andrade and Ferreiro, 1996; Mazvimbakupa et al., 2015; Araujo et al., 2018). The temperature is the main climatic factor affecting physiological processes during the grain filling period and therefore the yield itself (Holzkämper and Fuhrer, 2013). Agroecological conditions depend not only on edaphic factors in a certain region, but also on the application of cropping practices in the production of seed crops and on the existing climatic changes that bring restrictions in established cropping practices (Cicchino et al., 2010; Lobell et al., 2013; Mayer et al., 2014). Seed traits can be used in the initial investigation of genetic diversity. Great genetic variability was recorded in the grain productivity property based on genetic parameters (Nascimento-Júnior et al., 2018; Torres et al, 2019).

A chronological analysis of the varieties released over the last 90 years points out that a major promoter of the yield increase was an enhancement in seed number per plant. On the other hand, the individual seed size has not been changed over time (Ainsworth et al., 2012; Hu et al., 2013). Plant reproduction is based on the ratio between the number and size of the seed. Until now, there has been no strong evidence of the advantages of developing large seeds in different environmental conditions (Westoby et al., 1992). Seed morphological properties are made uniform in the technological processing of seed material to the state suitable for sowing. Grading of seed by shape and size is one of the most efficient methods of standardising physical and mechanical seed properties. The objective of the present study was to determine to what extent the seed produced under different production conditions and classified by the size and shape for each genotype, affected the differences and possible advantages of the initial development of seedlings (vigour) and total germination under various environmental temperature regimes.

\section{MATERIALS AND METHODS}

\section{Plant material and seed production and processing}

The hybrid seed of the following three commercial maize (Zea mays L.) genotypes was used in this study: ZP 684 (FAO 600), ZP 677 (FAO 600) and ZP 505 (FAO 500). The hybrids ZP 684 and ZP 677 are characterised with the yellow dent kernel type, while the hybrid ZP 505 is characterised with the flinty yellow dent kernel type.

Seed production of commercial hybrids had been established in two locations, Orahovo (O) (45 $\left.51^{\prime} \mathrm{N}, 19^{\circ} 46^{\prime} \mathrm{E}\right)$ and Plavna (P) $\left(45^{\circ} 20^{\prime} \mathrm{N}, 19^{\circ} 07^{\prime} \mathrm{E}\right)$, in 2017 . Seed crops were grown on meadow soil and alluvial deposit.

The seed crop production was performed according to all principles and rules of seed production (Official Gazette of the Republic of Serbia, 2006; issue 2006/06). Ears used in laboratory analyses were manually harvested. Shelling was done with laboratory shellers, while kernels were dried to $14 \%$ moisture in ovens at $35^{\circ} \mathrm{C}$.

According to the seed size and shape obtained by a precision sizer equipment (CEA. Carter Day International, Minneapolis, Minnesota, USA), the material was classified into three fractions: small, medium and large seeds, and then into two fractions according to the seed shape: flat and round seeds (Table 1). Finally, six fractions were obtained: small flat seed (SFS), small round seed (SRS), medium small flat seed (MSFS), medium small round seed (MSRS), large flat seed (LFS), and large round seed (LRS). The experimental seed material was not surface chemically protected.

\section{Laboratory testing}

Seventy-two samples were drawn for each seed fraction over hybrid combinations and two locations in 10 replicates. The laboratory tests included the determination of the following parameters for each hybrid combination, each location and each seed fraction: Fifty-seeds dry weight prior to germination (W1), 50 seedlings dry weight (W2), weight loss

Table 1. Dimensions of seed of various fractions: small flat seed (SFS), small round seed (SRS), medium small flat seed (MSFS), medium small round seed (MSRS), large flat seed (LFS), and large round seed (LRS).

\begin{tabular}{|c|c|c|c|c|c|c|}
\hline Hybrids & SFS & SRS & MSFS & MSRS & LFS & LRS \\
\hline ZP505 & $\geq 7.4<7.9<5.1$ & $\geq 7.4<7.9 \geq 5.1$ & $\geq 7.9<8.9<5.1$ & $\geq 7.9<8.9 \geq 5.1$ & $\geq 8.9<5.1$ & $\geq 8.9 \geq 5.1$ \\
\hline ZP677 & $\geq 6.2<7.0<5.1$ & $\geq 6.2<7.0 \geq 5.1$ & $\geq 7.0<7.8<5.1$ & $\geq 7.0<7.8 \geq 5.1$ & $\geq 7.8<5.1$ & $\geq 7.8 \geq 5.1$ \\
\hline ZP684 & $\geq 7.0<7.8<5.1$ & $\geq 7.0<7.8 \geq 5.1$ & $\geq 7.8<7.9<5.1$ & $\geq 7.8<7.9 \geq 5.1$ & $\geq 7.9<5.1$ & $\geq 7.9 \geq 5.1$ \\
\hline
\end{tabular}

$\geq$ lower sieve hole $\varnothing<$ upper sieve hole $\emptyset \geq /<$ shape separation sieve width \#. 
during germination $(\Delta \mathrm{W})$, vigour $(\mathrm{V})$, total seed germination $(\mathrm{G})$, and germination rate $(\mathrm{GR})$. The germination rate was estimated after the model coined by Krishnasamy and Seshu (1990):

GR $(\%)=($ Number of normal seedlings $(72,96, \ldots, 168 \mathrm{~h}) /$ Number normal seedlings $) \times 100$

Fifty seedlings were dried in an oven at $60^{\circ} \mathrm{C}$ for $48 \mathrm{~h}$. The seed weight loss during germination was determined on the basis of the endosperm dry residue weight (not presented) and dry seedlings weight.

Vigour, total germination and weight loss during germination were established by the between filter paper method in germination cabinets in the following way:

Treatment 1 TR1: (cold test) $10{ }^{\circ} \mathrm{C}$ for $7 \mathrm{~d}$ and $20 / 30{ }^{\circ} \mathrm{C}$ (alternately $7 \mathrm{~d} 16 / 8 \mathrm{~h}$ ).

Treatment 2 TR2: $20 / 30^{\circ} \mathrm{C}$ (alternately $7 \mathrm{~d} 16 / 8 \mathrm{~h}$ ).

Parameters of temperatures, humidity and light are presented in Table 2. The first evaluation was done after $72 \mathrm{~h}$ germination under optimum conditions, and then at every $24 \mathrm{~h}$ until the final germination. The criterion for assessing normality of seedlings was: the coleoptile grown minimally up to the seed size, primary root had hairs while the rudiments of secondary roots were visible. Total germination was determined on the seventh day $(168 \mathrm{~h})$ as prescribed by the standard method of International Seed Testing Association (ISTA) (ISTA, 2019).

Temperature and humidity were measured daily, while light intensity was measured annually with a digital light meter (MS6610, Mastech Group, Hong Kong, China).

\section{Statistical analysis}

The obtained experimental data were processed by the mathematical and statistical methods using the SPSS 19.0 statistical package (free version, IBM, Armonk, New York, USA).

Descriptive statistics was used to process obtained parameters. The ANOVA for factorial trial set up according to the randomised design was used to determine differences among observed maize hybrids (three) and locations (two), as well as their interactions. The magnitudes of effects of each factor, as well as their interactions, were estimated by the partial eta-squared coefficient that was then classified according to Cohen's gradation (Cohen, 1988). A relative dependence of traits was determined by the Pearson's coefficient of correlation and equations of linear regression at the probability levels of $5 \%$ and $1 \%$.

\section{RESULTS AND DISCUSSION}

\section{Morphological traits of seed}

The genotype, location $(\mathrm{p}<0.01)$ and fraction $(\mathrm{p}<0.05)$ affected the expression of the seed morphological traits (W1, W2 and $\Delta \mathrm{W}$ ). The significance of interaction effects differed in the stated traits (Table 3 ).

Round fractions had a greater weight than the flat ones. The highest differences were established in SFS between the hybrid ZP 505 and remaining two hybrids. Large fractions were almost equal in their weights for all genotypes. The effect of Genotype $\times$ Location and Genotype $\times$ Fraction interactions was the most important on the formation of this trait. To what extent the seed size will be expressed depends on genotype, production year and phenophase (Mayer et al., 2019). The size (dimensions) and the number of fractions have to be adjusted to genotype traits, i.e. to the composition of seed material for each genotype.

The relationship between W2 and seed size was not linear. A greater seedling weight was observed in flat fraction seeds. Significant differences were established over genotypes and the locations of their production. The Hybrid $\times$ Location interaction had the highest partial effect $(\eta=0.338)$. Hybrid $\times$ Fraction and Location $\times$ Fraction interactions were nonsignificant, while Hybrid $\times$ Location $\times$ Fraction interaction was significant (Table 4). The weight loss during germination was the highest in LRS, while there were nonsignificant differences among remaining fractions, nor there a linear relation with remaining traits.

Table 2. Temperature, relative humidity $(\mathrm{RH})$ and light intensity in the germination cabinet.

\begin{tabular}{|c|c|c|c|c|c|c|c|}
\hline & \multicolumn{3}{|c|}{ Temperature } & \multirow[b]{2}{*}{$\mathrm{RH}$} & \multicolumn{3}{|c|}{ Light intensity } \\
\hline & $10^{\circ} \mathrm{C}$ & $20^{\circ} \mathrm{C}$ & $30^{\circ} \mathrm{C}$ & & Right & Medium & Left \\
\hline & 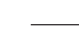 & ${ }^{\circ} \mathrm{C}$ & - & $\%$ & & $-1 \mathrm{x}$ & - \\
\hline Mean & 10.0 & 20.2 & 29.4 & 42 & 1206 & 1073 & 1200 \\
\hline
\end{tabular}


Table 3. Effect of the genotype, location and fraction on the expression of seed morphological traits: 50 seeds dry weight prior to germination (W1), 50 seedlings dry weight (W2), weight loss during germination $(\Delta \mathrm{W})$.

\begin{tabular}{|c|c|c|c|c|c|c|c|c|}
\hline \multirow[b]{2}{*}{ Traits } & \multirow[b]{2}{*}{ Fraction } & \multicolumn{2}{|c|}{ ZP505 } & \multicolumn{2}{|c|}{ ZP677 } & \multicolumn{2}{|c|}{ ZP684 } & \multirow{2}{*}{$\begin{array}{l}\text { Average } \\
\text { of fraction }\end{array}$} \\
\hline & & Orahovo & Plavna & Orahovo & Plavna & Orahovo & Plavna & \\
\hline & & 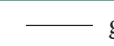 & - & - & - & - & - & $\mathrm{g}$ \\
\hline \multirow[t]{6}{*}{ W1 } & SFS & 14.02 & 13.48 & 11.89 & 11.89 & 11.59 & 11.87 & 12.46 \\
\hline & SRS & 14.62 & 14.65 & 12.57 & 12.48 & 14.69 & 14.64 & 13.94 \\
\hline & MSFS & 15.22 & 14.88 & 14.01 & 14.04 & 14.44 & 14.46 & 14.51 \\
\hline & MSRS & 16.75 & 16.45 & 15.51 & 15.40 & 17.30 & 17.15 & 16.43 \\
\hline & LFS & 16.51 & 16.24 & 16.37 & 16.18 & 17.03 & 17.08 & 16.57 \\
\hline & LRS & 18.49 & 18.18 & 18.61 & 18.53 & 19.43 & 19.65 & 18.82 \\
\hline \multicolumn{9}{|c|}{$\mathrm{R}^{2}=0.965$ (adjusted $\left.\mathrm{R}^{2}=0.961\right)$} \\
\hline \multirow{8}{*}{$\begin{array}{l}\text { Average of locations } \\
\text { Average of hybrids } \\
\text { W2 }\end{array}$} & & 15.94 & 15.65 & 14.83 & 14.75 & 15.75 & 15.81 & \\
\hline & & \multicolumn{2}{|c|}{15.79} & \multicolumn{2}{|c|}{14.79} & \multicolumn{2}{|c|}{15.78} & \\
\hline & SFS & 1.18 & 0.72 & 0.71 & 1.01 & 0.92 & 1.17 & 0.89 \\
\hline & SRS & 0.94 & 0.73 & 0.71 & 1.05 & 0.69 & 1.20 & 1.00 \\
\hline & MSFS & 1.01 & 0.76 & 0.76 & 1.17 & 0.86 & 1.41 & 0.96 \\
\hline & MSRS & 1.23 & 0.64 & 0.73 & 1.06 & 0.71 & 1.40 & 1.00 \\
\hline & LFS & 1.07 & 0.71 & 0.85 & 1.19 & 0.79 & 1.39 & 0.91 \\
\hline & LRS & 1.00 & 0.63 & 0.70 & 0.99 & 0.73 & 1.41 & \\
\hline \multicolumn{9}{|c|}{$\mathrm{R}^{2}=0.582\left(\right.$ adjusted $\left.\mathrm{R}^{2}=0.535\right)$} \\
\hline \multirow{8}{*}{$\begin{array}{l}\text { Average of locations } \\
\text { Average of hybrids } \\
\Delta \mathrm{W}\end{array}$} & & 1.07 & 0.70 & 0.74 & 1.08 & 0.78 & 1.33 & \\
\hline & & \multicolumn{2}{|c|}{0.89} & \multicolumn{2}{|c|}{0.91} & \multicolumn{2}{|c|}{1.06} & \\
\hline & SFS & 0.60 & 0.54 & 0.52 & 1.03 & 0.60 & 0.68 & 0.79 \\
\hline & SRS & 0.56 & 0.67 & 0.43 & 0.86 & 0.85 & 0.79 & 0.74 \\
\hline & MSFS & 0.88 & 0.56 & 0.53 & 1.23 & 0.78 & 0.75 & 0.80 \\
\hline & MSRS & 0.66 & 0.62 & 0.58 & 1.04 & 0.70 & 0.84 & 0.81 \\
\hline & LFS & 0.92 & 0.65 & 0.54 & 1.09 & 0.77 & 0.81 & 12.46 \\
\hline & LRS & 1.04 & 0.72 & 0.44 & 1.16 & 0.71 & 0.80 & 13.94 \\
\hline \multicolumn{9}{|c|}{$\mathrm{R}^{2}=0.299$ (adjusted $\left.\mathrm{R}^{2}=0.222\right)$} \\
\hline Average of locations & & 0.78 & 0.63 & 0.51 & 1.07 & 0.74 & 0.78 & \\
\hline Average of hybrids & & \multicolumn{2}{|c|}{0.70} & \multicolumn{2}{|c|}{0.79} & \multicolumn{2}{|c|}{0.76} & \\
\hline
\end{tabular}

SFS: Small flat seed; SRS: small round seed; MSFS: medium small flat seed; MSRS: medium small round seed; LFS: large flat seed; LRS: large round seed.

Table 4. Results of ANOVA of principal and interaction effects and the results of partial effects.

\begin{tabular}{|c|c|c|c|c|c|c|}
\hline & \multicolumn{2}{|l|}{ W1 } & \multicolumn{2}{|l|}{$\mathrm{W} 2$} & \multicolumn{2}{|l|}{$\Delta \mathrm{W}$} \\
\hline & Partial Eta squared & $\mathrm{F}$ test & Partial Eta squared & $F$ test & Partial Eta squared & $F$ test \\
\hline Hybrid (H) & 0.382 & $* *$ & 0.069 & $* *$ & 0.010 & $* *$ \\
\hline Location (L) & 0.007 & $* *$ & 0.086 & $* *$ & 0.043 & $* *$ \\
\hline Fraction (F) & 0.923 & $*$ & 0.022 & $*$ & 0.024 & $*$ \\
\hline $\mathrm{H} \times \mathrm{L}$ & 0.014 & $* *$ & 0.338 & $* *$ & 0.150 & $* *$ \\
\hline $\mathrm{H} \times \mathrm{F}$ & 0.433 & $* *$ & 0.018 & ns & 0.026 & ns \\
\hline $\mathrm{L} \times \mathrm{F}$ & 0.002 & ns & 0.015 & ns & 0.002 & ns \\
\hline $\mathrm{H} \times \mathrm{L} \times \mathrm{F}$ & 0.011 & $*$ & 0.027 & $*$ & 0.026 & ns \\
\hline
\end{tabular}

$\mathrm{W} 1: 50$ seeds dry weight prior to germination; W2: 50 seedlings dry weight; $\Delta \mathrm{W}$ : weight loss during germination. $*, * *$ Significant at the 0.05 and 0.01 probability levels, respectively; ns: nonsignificant at the 0.05 probability level.

\section{Physiological traits of seed}

Parametric tests showed that physiological traits depended on genotype, location and fraction $(\mathrm{p}<0.05, \mathrm{p}<0.01)$ (Table 5). The effects of genotype and location and their interaction particularly stood out. The impacts of the temperature on physiological traits differed.

A total proportion of factors in the variance for total germination was $\mathrm{R}^{2}=0.694$ (Table 6). Genotype and location had a crucial effect. Total germination by seed size was uniform, small differences were observed between round and flat fractions. The temperature regime did not affect significantly variability of this trait (Figure 1). 
Vigour estimated after $72 \mathrm{~h}$ germination was high in all observed samples. All observed factors significantly affected seedling emergence. Combinations with genotype and location $(\mathrm{p}<0.01 ; 0.05)$ were prominent among observed factor combinations.

Significant differences in germination were observed between flat and round fractions in each reading $(72 \mathrm{~h} \rightarrow 168 \mathrm{~h})$. Germination was already $100 \%$ in the first reading, and $>90 \%$ in $70 \%$ of samples. On the other hand, in the first reading, vigour ranged from $0 \%$ to $100 \%$ and from $52 \%$ to $100 \%$ in TR1 and TR2, respectively. The number of newly germinated seedlings was abruptly increasing from 72 to $120 \mathrm{~h}$, and then this number became uniform in samples (Figures 2A-2B).

The parametric tests confirmed the significance of the genotype, location and fractions for the germination rate (coefficient of determination was high, $\mathrm{R}^{2}=0.609$ ). Flat fractions emerged faster than the round ones (Figures 2C-2D). This is in accordance with results obtained in field trials by Graven and Carter (1990). The seed size did not indicate the significance of this trait (Figures 2C-2D).

The classification of seeds by fractions, contributes to the more uniform weight of the endosperm. This weight is important for the uniform seed vigour and germination. Small endosperm seeds are more susceptible (Wann, 1980), and dysfunction of storage reserve often occurs (Styer and Cantliffe, 1983), which is the main cause of their poor viability. Uniformity, high seedling emergence rate, high-vigour seeds and high total seed germination results in high yield (Funk et al., 1962; Egli et al., 2010).

\section{Relationship between morphological and physiological traits for observed factors}

The results of the correlation analysis and the regression equation point out that conditions for the seed formation (production location) and temperature regime for germination testing, differently affected the physiological process of seed germination of maize hybrids. The values of the coefficient $\mathrm{R}^{2}$ ranged from insignificant to absolute determination and correlation. Such coefficient values indicate that the physiological process proceeding during germination of hybrid maize seeds depended on many factors, but to a different extent for each genotype and various temperature regimes. By standardisation of morphological properties of hybrid seeds produced in different locations we did not uniform to the same degree physiological traits that were expressed during germination.

Obtained results also indicate the significance of agroecological conditions for the formation of hybrid seed properties. As confirmed by these studies (Mi et al., 2018.), the knowledge on the effect of local agroecological conditions on the formation of seed traits was particularly important. Total germination for all fractions in the location $\mathrm{P}$ was determined almost completely $(>90 \%)$ by vigour (Figure $3 \mathrm{~A}$ ). The relationship between vigour and germination was reflected in the germination rate. The regression lines obtained within this location were also uniform over genotypes (Figures 3A-3D).

Within the same genotype, physiological properties were largely affected by agroecological conditions during the seed formation period. The effects of locations on total germination and vigour of seeds classified in fractions are presented in Figure 4.

Table 5. Results of ANOVA of principal and interaction effects and the results of partial eta-squared effects are presented.

\begin{tabular}{|c|c|c|c|c|c|c|}
\hline & \multicolumn{2}{|l|}{ Vigour (V) } & \multicolumn{2}{|c|}{ Total seed germination $(\mathrm{G})$} & \multicolumn{2}{|c|}{ Germination rate (GR) } \\
\hline & Partial Eta squared & F test & Partial Eta squared & F test & Partial Eta squared & F test \\
\hline Hybrid (H) & 0.252 & ** & 0.390 & ** & 0.316 & $* *$ \\
\hline Location (L) & 0.116 & $* *$ & 0.150 & $* *$ & 0.400 & $* *$ \\
\hline Fraction $(\mathrm{F})$ & 0.064 & $* *$ & 0.037 & $* *$ & 0.045 & $* *$ \\
\hline Temperature $(\mathrm{T})$ & 0.009 & $*$ & 0.023 & $* *$ & 0.000 & ns \\
\hline $\mathrm{H} \times \mathrm{L}$ & 0.423 & $* *$ & 0.207 & $* *$ & 0.425 & $* *$ \\
\hline $\mathrm{H} \times \mathrm{F}$ & 0.035 & $*$ & 0.070 & $* *$ & 0.022 & ns \\
\hline $\mathrm{H} \times \mathrm{T}$ & 0.080 & $* *$ & 0.141 & $* *$ & 0.228 & $* *$ \\
\hline $\mathrm{L} \times \mathrm{F}$ & 0.033 & $* *$ & 0.041 & $* *$ & 0.036 & $* *$ \\
\hline $\mathrm{L} \times \mathrm{T}$ & 0.037 & $* *$ & 0.001 & ns & 0.059 & $* *$ \\
\hline $\mathrm{F} \times \mathrm{T}$ & 0.004 & ns & 0.009 & ns & 0.004 & ns \\
\hline $\mathrm{H} \times \mathrm{L} \times \mathrm{F}$ & 0.038 & $* *$ & 0.043 & $* *$ & 0.027 & ns \\
\hline $\mathrm{H} \times \mathrm{L} \times \mathrm{T}$ & 0.077 & $* *$ & 0.025 & $* *$ & 0.068 & $* *$ \\
\hline $\mathrm{H} \times \mathrm{F} \times \mathrm{T}$ & 0.009 & ns & 0.007 & ns & 0.015 & ns \\
\hline $\mathrm{L} \times \mathrm{F} \times \mathrm{T}$ & 0.008 & ns & 0.019 & $*$ & 0.003 & ns \\
\hline $\mathrm{H} \times \mathrm{L} \times \mathrm{F} \times \mathrm{T}$ & 0.022 & $\mathrm{~ns}$ & 0.031 & $*$ & 0.009 & ns \\
\hline
\end{tabular}

*,**Significant at the 0.05 and 0.01 probability levels, respectively; ns: nonsignificant at the 0.05 probability level. 
Table 6. Effects of the genotype, location and the fraction on the expression of seed physiological traits: vigour (V), total seed germination (G), germination rate (GR), established in treatments TR1 and TR2.

\begin{tabular}{|c|c|c|c|c|c|c|c|c|c|c|c|c|c|c|}
\hline \multirow[b]{3}{*}{ Traits } & \multirow[b]{3}{*}{ Fraction } & \multicolumn{4}{|c|}{ ZP505 } & \multicolumn{4}{|c|}{ ZP677 } & \multicolumn{4}{|c|}{ ZP684 } & \multirow{3}{*}{$\begin{array}{l}\text { Average } \\
\text { of } \\
\text { fraction }\end{array}$} \\
\hline & & \multicolumn{2}{|c|}{ Orahovo } & \multicolumn{2}{|c|}{ Plavna } & \multicolumn{2}{|c|}{ Orahovo } & \multicolumn{2}{|c|}{ Plavna } & \multicolumn{2}{|c|}{ Orahovo } & \multicolumn{2}{|c|}{ Plavna } & \\
\hline & & TR1 & TR2 & TR1 & TR2 & TR1 & TR2 & TR1 & TR2 & TR1 & TR2 & TR1 & TR2 & \\
\hline & & & & & & & . & & & & -9 & & & $\%$ \\
\hline \multirow[t]{6}{*}{ V } & SFS & 87.0 & 87.8 & 71.4 & 74.2 & 85.6 & 86.6 & 85.6 & 86.6 & 48.2 & 76.4 & 86.2 & 93.8 & 80.8 \\
\hline & SRS & 70.0 & 77.8 & 72.6 & 74.0 & 82.0 & 83.2 & 82.0 & 83.2 & 34.4 & 69.4 & 86.8 & 92.8 & 75.7 \\
\hline & MSFS & 80.6 & 83.8 & 68.2 & 62.4 & 81.8 & 91.8 & 81.8 & 91.8 & 54.4 & 78.0 & 90.8 & 96.6 & 80.2 \\
\hline & MSRS & 78.8 & 87.4 & 68.2 & 60.8 & 85.8 & 79.2 & 85.8 & 79.2 & 37.6 & 61.8 & 95.0 & 89.4 & 75.8 \\
\hline & LFS & 75.6 & 84.6 & 60.0 & 61.0 & 95.2 & 89.6 & 95.2 & 89.6 & 57.0 & 75.6 & 92.6 & 88.8 & 80.4 \\
\hline & LRS & 74.2 & 81.6 & 53.4 & 56.6 & 80.2 & 69.6 & 80.2 & 69.6 & 41.2 & 61.2 & 92.6 & 88.4 & 70.7 \\
\hline \multicolumn{15}{|c|}{$\mathrm{R}^{2}=0.622\left(\right.$ adjusted $\left.\mathrm{R}^{2}=0.580\right)$} \\
\hline \multirow{3}{*}{\multicolumn{2}{|c|}{$\begin{array}{l}\text { Average of treatments } \\
\text { Average of location } \\
\text { Average of hybrids }\end{array}$}} & 77.70 & 83.83 & 65.63 & 64.83 & 85.10 & 83.33 & 85.10 & 83.33 & 45.47 & 70.40 & 90.67 & 91.63 & \\
\hline & & \multicolumn{2}{|c|}{80.77} & \multicolumn{2}{|c|}{65.23} & & & \multicolumn{2}{|c|}{84.22} & \multicolumn{4}{|c|}{91.15} & \\
\hline & & \multicolumn{4}{|c|}{73.00} & \multicolumn{4}{|c|}{84.22} & \multicolumn{4}{|c|}{74.54} & \\
\hline \multirow[t]{6}{*}{ G } & SFS & 96.4 & 88.8 & 79.6 & 74.6 & 91.2 & 95.4 & 85.8 & 97.6 & 87.2 & 94.8 & 87.6 & 93.8 & 89.4 \\
\hline & SRS & 89.6 & 77.8 & 87.2 & 74.6 & 87.8 & 92.2 & 87.8 & 91.4 & 83.2 & 92.2 & 86.8 & 93.0 & 87.0 \\
\hline & MSFS & 92.2 & 85.8 & 78.8 & 63.6 & 91.6 & 97.8 & 93.8 & 97.2 & 91.4 & 96.4 & 91.4 & 96.6 & 89.7 \\
\hline & MSRS & 93.2 & 87.4 & 80.0 & 60.8 & 95.2 & 96.4 & 90.4 & 95.6 & 87.8 & 89.0 & 95.0 & 89.8 & 88.4 \\
\hline & LFS & 88.0 & 85.0 & 73.2 & 61.0 & 97.6 & 94.2 & 88.8 & 95.4 & 96.4 & 96.2 & 92.6 & 89.0 & 88.1 \\
\hline & LRS & 90.4 & 82.8 & 68.6 & 56.6 & 92.0 & 93.4 & 84.6 & 94.2 & 91.8 & 90.0 & 93.0 & 89.0 & 85.5 \\
\hline \multicolumn{15}{|c|}{$\mathrm{R}^{2}=0.694$ (adjusted $\left.\mathrm{R}^{2}=0.661\right)$} \\
\hline \multirow{3}{*}{\multicolumn{2}{|c|}{$\begin{array}{l}\text { Average of treatments } \\
\text { Average of location } \\
\text { Average of hybrids }\end{array}$}} & 91.63 & 84.60 & 77.90 & 65.20 & 92.57 & 94.90 & 88.53 & 95.23 & 89.63 & 93.10 & 91.07 & 91.87 & \\
\hline & & 88 & 12 & & & & & & 88 & & & & & \\
\hline & & & 79. & & & & & & & & 91 & & & \\
\hline GR & SFS & 90.2 & 98.7 & 89.6 & 99.3 & 93.9 & 90.8 & 99.7 & 100.0 & 53.5 & 79.9 & 98.1 & 100.0 & 91.1 \\
\hline & SRS & 78.2 & 100.0 & 83.0 & 99.1 & 93.2 & 90.3 & 100.0 & 100.0 & 39.5 & 74.2 & 100.0 & 99.7 & 88.1 \\
\hline & MSFS & 87.4 & 97.7 & 86.5 & 97.7 & 89.2 & 93.8 & 100.0 & 100.0 & 58.5 & 80.7 & 99.2 & 100.0 & 90.9 \\
\hline & MSRS & 84.4 & 100.0 & 85.0 & 100.0 & 90.1 & 82.3 & 100.0 & 100.0 & 42.1 & 68.1 & 100.0 & 99.5 & 87.6 \\
\hline & LFS & 85.7 & 99.4 & 81.3 & 100.0 & 97.5 & 95.1 & 100.0 & 100.0 & 58.7 & 77.9 & 100.0 & 99.7 & 91.3 \\
\hline & LRS & 82.2 & 98.6 & 78.0 & 100.0 & 87.2 & 74.2 & 100.0 & 100.0 & 44.4 & 65.4 & 99.5 & 99.3 & 85.7 \\
\hline & & & & & & $=0.609$ & idjusted & ${ }^{2}=0.56$ & & & & & & \\
\hline Averag & treatments & 84.68 & 99.07 & 83.90 & 99.35 & 91.85 & 87.75 & 99.95 & 100.00 & 49.45 & 74.37 & 99.47 & 99.70 & \\
\hline Averag & location & & .88 & & & & & & .98 & & & & 58 & \\
\hline Averag & hybrids & & 91. & & & & & & & & 80 & 75 & & \\
\hline
\end{tabular}

SFS: Small flat seed; SRS: small round seed; MSFS: medium small flat seed; MSRS: medium small round seed; LFS: large flat seed; LRS: large round seed; TR1: $10^{\circ} \mathrm{C}$ for $7 \mathrm{~d}$ and $20 / 30{ }^{\circ} \mathrm{C}$ (alternately $7 \mathrm{~d} 16 / 8 \mathrm{~h}$ ); TR2: $20 / 30{ }^{\circ} \mathrm{C}$ (alternately $7 \mathrm{~d} 16 / 8 \mathrm{~h}$ ).

The coefficients of regression indicate different effects of locations and temperatures $\left(0.300<\mathrm{R}^{2}<1\right)$. The relationship between vigour and germination was almost total in the location $\mathrm{P}$, while the difference among genotypes was nonsignificant. Stress is one of the most important reasons for poor germination. Temperature, and particularly water stress, can inhibit seed germination and uniformity, which is related to the crop composition and reproductive development of plants (Kranner et al., 2010).

Grain yield is a primary function of the number of developed kernels (Amelong et al., 2015), while traits of flowers (pollen and silk) determine seed setting (Spitkó et al., 2014). The variation in seed weight is genetically determined, but it is often a result of adjusting to the number of seeds and consequently to yield (Egli, 2006; Sadras, 2007). Therefore, the correlation between seed weight and seed germination is important for the determination of seed quality. Estimated coefficients of correlation point out to a great importance of the production location. The effect of the location $\mathrm{P}$ was very great on the emergence of the first seedlings in all seed shapes and seed sizes except for MSRS (Figures 5B-5D). The effect of the location $\mathrm{O}$ was great on vigour in fractions SFS and MSRS $(\mathrm{p}<0.01,0.05)$ (Figures 5A-5C).

The temperature conditions did not alter the relationship of the weight and vigour. The variation in vigour under different temperature regimes was observed in SRS and MSRS (Figures 6A-6D). 
Figure 1. Effects of locations Orahovo (O) and Plavna (P), treatments (TR1, TR2), fractions: large flat seed (LFS), large round seed (LRS), medium small flat seed (MSFS), medium small round seed (MSRS), small flat seed (SFS), small round seed (SRS), and genotypes on total seed germination (G).

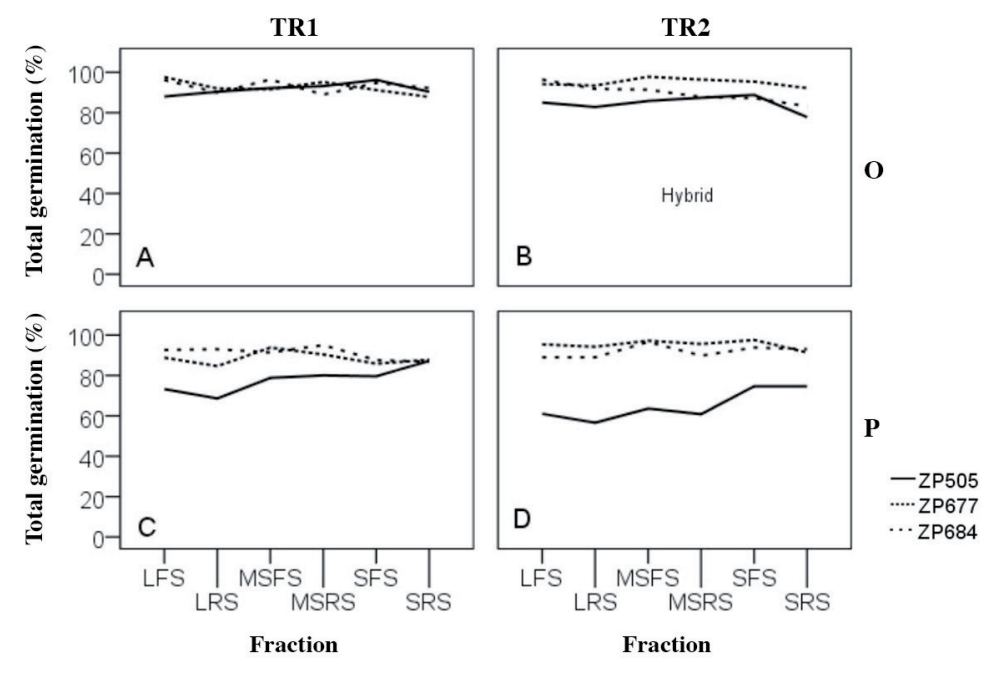

Each value refers to the average of 10 replicates (\%)

TR1: Cold test; TR2: alternately $20 / 30^{\circ} \mathrm{C}$.

Figure 2. Effects of treatments TR1 (cold test) and TR2 $\left(20 / 30{ }^{\circ} \mathrm{C}\right)$ on mean values of normal seedlings (A, B) and germination rate $(C, D)$ over hours of germination by fraction: large flat seed (LFS), large round seed (LRS), medium small flat seed (MSFS), medium small round seed (MSRS), small flat seed (SFS), and small round seed (SRS). Mean value of three hybrids.
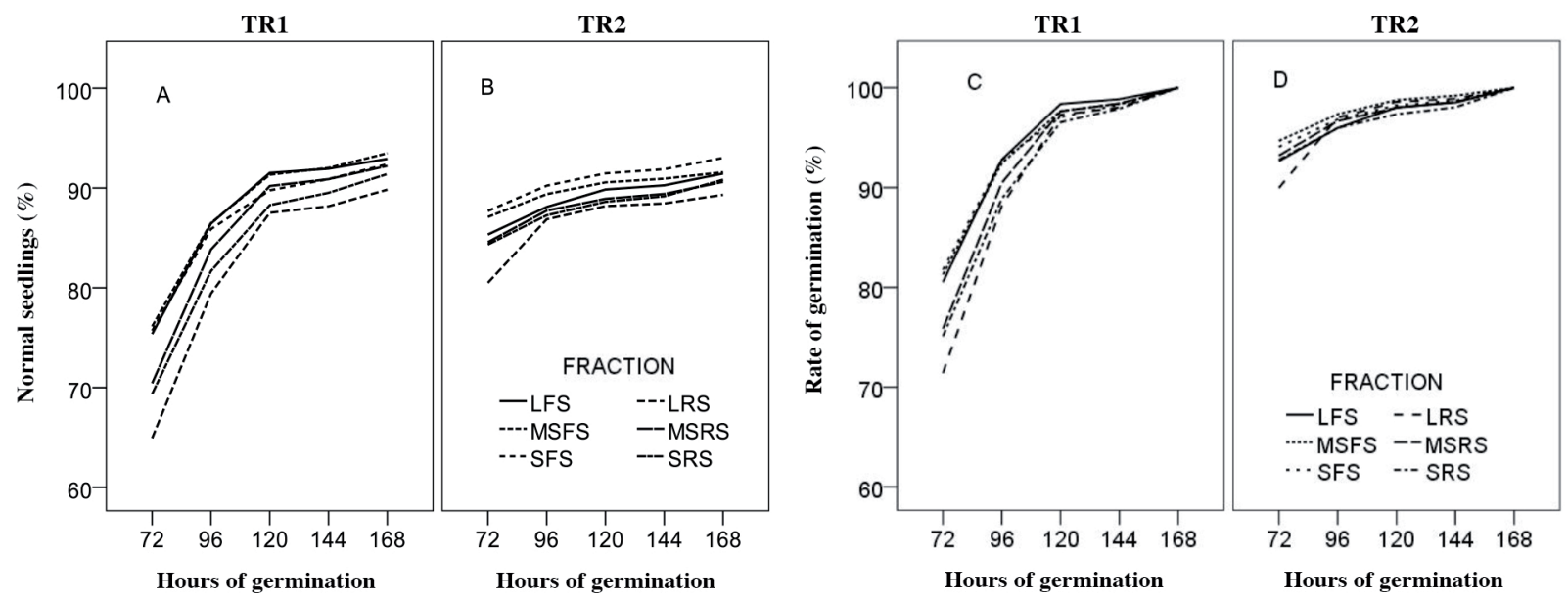

Each value refers to the average of rate of germination of three hybrids over six fraction (\%).

TR1: Cold test; TR2: alternately $20 / 30{ }^{\circ} \mathrm{C}$. 
Figure 3. Effects of locations Orahovo $(O)$ and Plavna $(P)$ on the relationship between vigour and total germination over hybrid combinations and fractions: small flat seed (SFS), medium small flat seed (MSFS), large flat seed (LFS), small round seed (SRS), medium small round seed (MSRS) and large round seed (LRS).
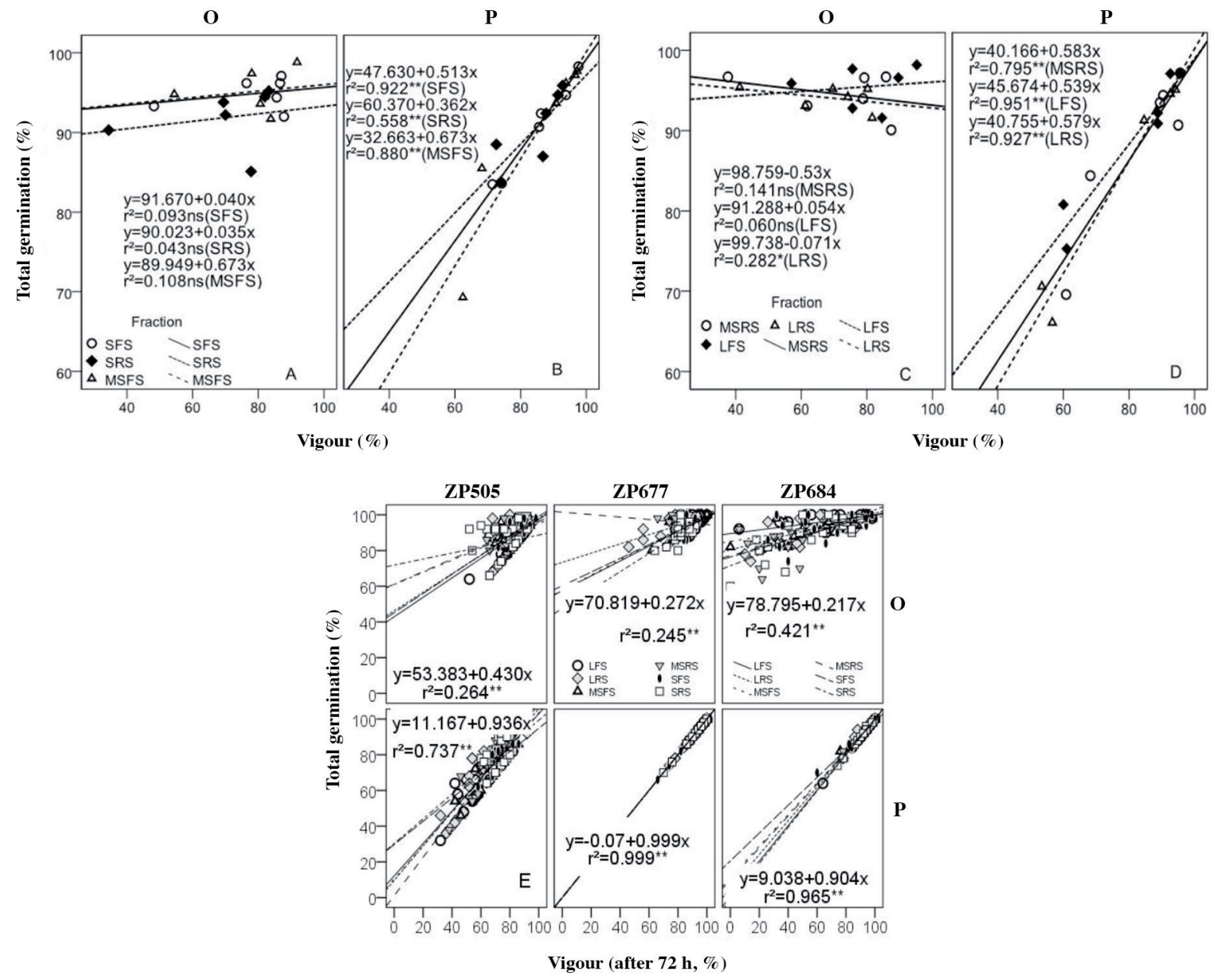

y: Estimated values total germination; $\mathrm{r}^{2}$ : squared Pearson correlation coefficient (coefficients of determination).

$*$,**Significant at the 0.05 and 0.01 probability levels, respectively. 
Figure 4. Effects of locations Orahovo (O) and Plavna (P) and treatments TR1 (cold test) and TR2 (20/30 $\left.{ }^{\circ} \mathrm{C}\right)$ on total germination and vigour of three hybrids seeds classified in fractions.

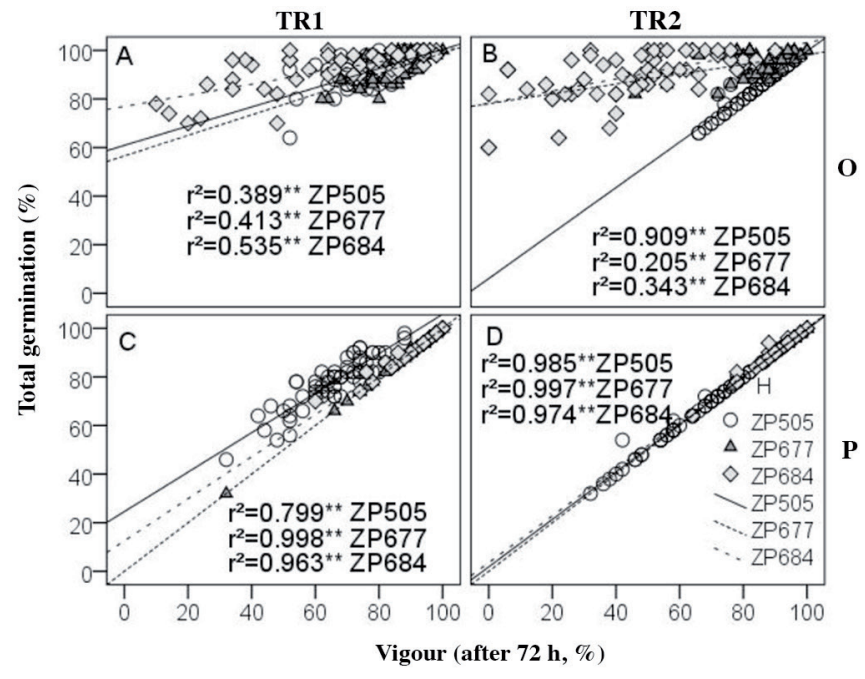

$r^{2}$ : Squared Pearson correlation coefficient (coefficients of determination).

*, **Significant at the 0.05 and 0.01 probability levels, respectively.

Figure 5. Effects of 50 seeds dry weight and vigour over fractions small flat seed (SFS), medium small flat seed (MSFS), small round seed (SRS) (A, B), large flat seed (LFS), medium small round seed (MSRS) and large round seed (LRS) (C, D) of averages of three hybrids seeds (ZP505, ZP677, ZP684).
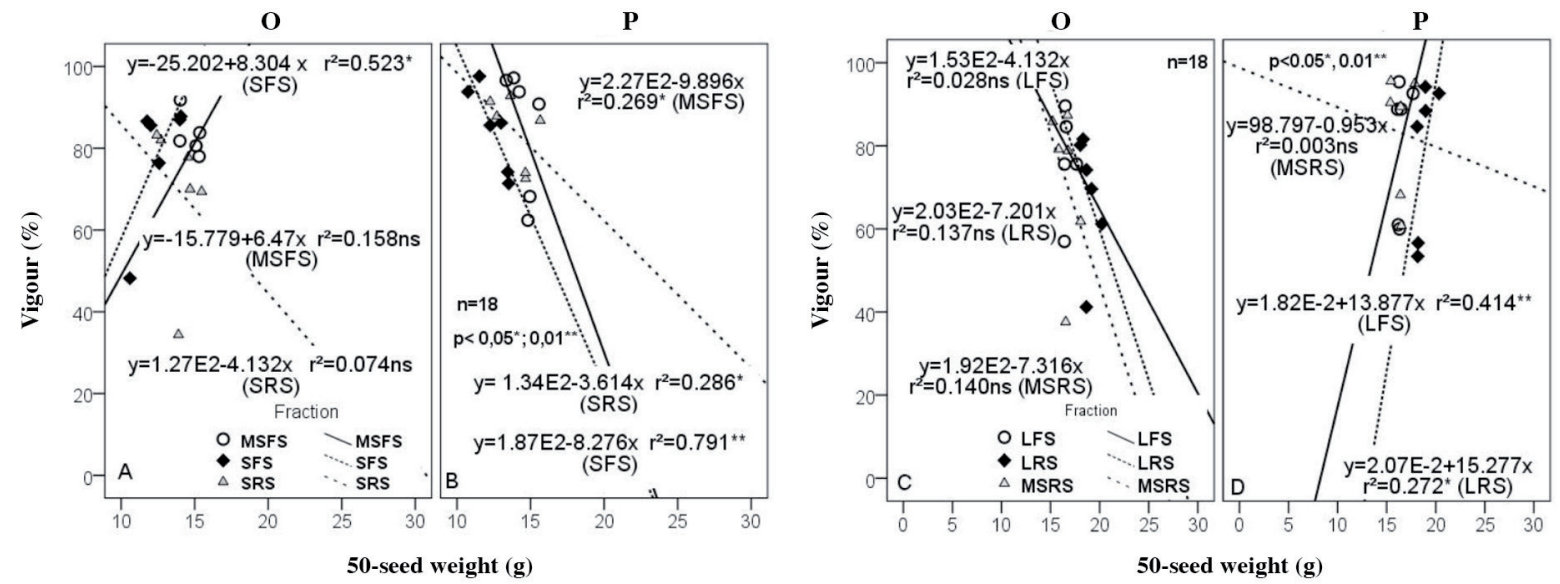

$\mathrm{y}$ : Estimated values of vigour for seed different fraction over location; O: Orahovo; P: Plavna; $\mathrm{r}^{2}$ : squared Pearson correlation coefficient (coefficients of determination)

$*$, **Significant at the 0.05 and 0.01 probability levels, respectively. 
Figure 6. Relationship between 50 seeds dry weight and vigour, partially over fractions small flat seed (SFS), small round seed (SRS), medium small flat seed (MSFS) (A, B), large flat seed (LFS), medium small round seed (MSRS) and large round seed (LRS) (C, D) observed in the TR1 and TR2, of average of three hybrids (ZP505, ZP677, ZP684).
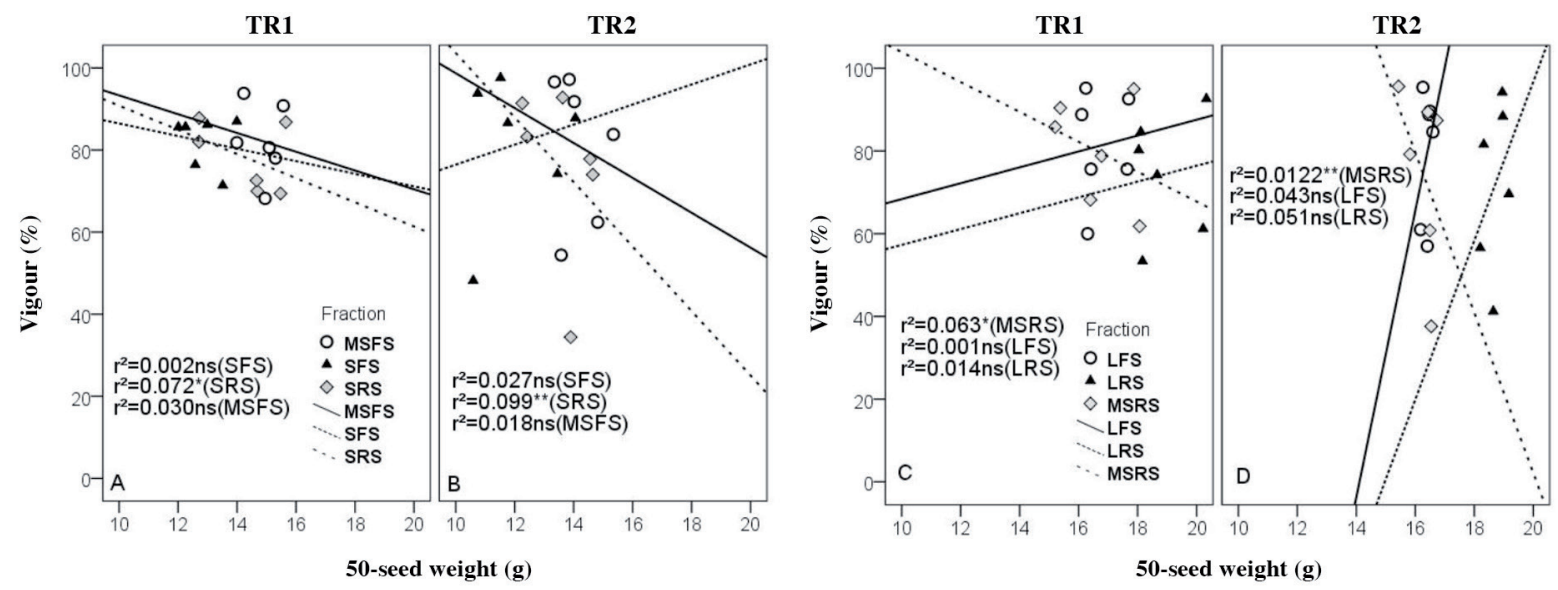

TR1: alternately $20 / 30^{\circ} \mathrm{C}, \mathrm{TR} 2$ : cold test; $\mathrm{r}^{2}$ : squared Pearson correlation coefficient (coefficients of determination). $*, * *$ Significant at the 0.05 and 0.01 probability levels, respectively.

\section{CONCLUSIONS}

Obtained results indicate that the effects of shape and size of hybrid maize seed on the expression of seed traits were significant. Small flat fractions had more rapid emergence of seedlings than large fractions. Round seeds were more susceptible and seed size had a greater effect on vigour. In different locations, production of the hybrid seed and germination temperature regimes showed different effects on the expression of seed traits over hybrid combinations.

The greatest correlation of total germination was established with vigour in all three hybrid combinations, in Plavna and under both temperature regimes.

The correlation between seed weight and germination was significant for small fractions. There were nonsignificant differences for temperature regimes. It can be concluded that the technological seed processing over seed fractions is justified. Seed grading over the size and shape provides the selection of seed fractions for stable production.

\section{ACKNOWLEDGEMENTS}

We thank the Ministry of Education, Science and Technological Development, Republic of Serbia, for the financial support on the Project TR31037.

\section{REFERENCES}

Ainsworth, E.A., Yendrek, C.R., Skoneczka, J.A., and Long, S.P. 2012. Accelerating yield potential in soybean: potential targets for biotechnological improvement. Plant, Cell and Environment 35(1):38-52.

Amelong, A., Gambín, B.L., Severini, A.D., and Borrás, L. 2015. Predicting maize kernel number using QTL information. Field Crops Research 172:119-131. doi:10.1016/j.fcr.2014.11.014.

Anders, A., Markowski, P., Konopka, S., Kaliniewicz, Y., Lipinski, A.J., and Choszcz, D.J. 2020. Effect of seeding rate on selected physical parameters and biomass yield of maize. Chilean Journal of Agricultural Research 80:171-180. doi:10.4067/S0718-58392020000200171.

Andrade, F.H., and Ferreiro, M.A. 1996. Reproductive growth of maize, sunflower and soybean at different source levels during grain filling. Field Crops Research 48:155-165. doi:10.1016/S0378-4290(96)01017-9.

Araujo, M.E.V., Barbosa, E.G., Gomes, F.A., Teixeira, I.R., Lisboa, C.F., Araújo, R.S.L., et al. 2018. Physical properties of sesame seeds harvested at different maturation stages and thirds of the plant. Chilean Journal of Agricultural Research 78:495-502. 
Asare, D.K., Frimpong, J.O., Ayeh, E.O., and Amoatey, H.M. 2011. Water use efficiencies of maize cultivars grown under rainfed conditions. Agricultural Sciences 2:125-130. doi:10.4236/as.2011.22018.

Bergamaschi, H., Wheeler, T.R., Challinor, A.J., Comiran, F., and Machado H.B.M. 2007. Maize yield and rainfall on different spatial and temporal scales in southern Brazil. Pesquisa Agropecuária Brasileira 42:603-613.

Chen, C., Lei, C., Deng, A., Qian, C., Hoogmoed, W., and Zhang. W. 2011. Will higher minimum temperatures increase corn production in Northeast China? An analysis of historical data over 1965-2008. Agricultural and Forest Meteorology 151:1580-1588. doi:10.1016/j.agrformet.2011.06.013.

Cicchino, M., Rattalino, E.J.I., Uribelarrea, M., and Otegui, M.E. 2010. Heat stress in field-grown maize: Response of physiological determinants of grain yield. Crop Science 50:1438-1448. doi:10.2135/cropsci2009.10.0574.

Cohen, J. 1988. Statistical power analysis for the behavioral sciences. 4th ed. Academic Press, New York, USA doi:10.1016/j.agrformet.2012.09.004.

Egli, D.B. 2006. The role of seed in the determination of yield of grain crops. Australian Journal of Agricultural Research 57:1237-1247.

Egli, D.B., Hamman, B., and Rucker, M. 2010. Seed vigor and uniformity of seedling emergence in soybean. Seed Technology 32:87-95.

Egli, D.B., and Rucker, M. 2012. Seed vigor and the uniformity of emergence of corn seedlings. Crop Science 52:2774-2782. doi:10.2135/cropsci2012.01.0064.

Funk, C.F., Anderson, J.C., Johnson, M.W., and Atkinson, R.W. 1962. Effect of seed source and seed age on field and laboratory performance of field corn. Crop Science 2:318-320.

Graven, L.M., and Carter, P.R. 1990. Seed size/shape and tillage system effect on corn growth and grain yield. Journal of Production Agriculture 3:445-452. doi:10.2134/jpa1990.0445.

Holzkämper, A., and Fuhrer, P.C.J. 2013. Identifying climatic limitations to grain maize yield potentials using a suitability evaluation approach. Agricultural and Forest Meteorology 168:149-159.

Hu, Z., Zhang, H., Kan, G., Ma, D., Zhang, D., Shi, G., et al. 2013. Determination of the genetic architecture of seed size and shape via linkage and association analysis in soybean (Glycine max L. Merr.) Genetica 141(4-6):247-254.

ISTA. 2019. Rules for testing seeds. International Seed Testing Association (ISTA), Zurich, Switzerland.

Kranner, I., Minibayeva, F.V., Beckett, R.P., and Seal, C.E. 2010. What is stress? Concepts, definitions and applications in seed science. New Phytologist 188:655-673. doi:10.1111/j.1469-8137.2010.03461.x.

Krishnasamy, V., and Seshu, D.V. 1990. Germination after accelerated aging and associated characters in rice varieties. Seed Science and Technology 18:353-359.

Lobell, D.B., Hammer, G.L., McLean, G., Messina, C., Roberts, M.J., and Schlenker, W. 2013. The critical role of extreme heat for maize production in the United States. Nature Climate Change 3:497-501. doi:10.1038/nclimate 1832.

Mayer, L.I., Cirilo, A.G., and Maddonni, G.A. 2019. Kernel hardness-related traits in response to heat stress during the grainfilling period of maize crops. Crop Science 58:1-15. doi:10.2135/cropsci2018.04.0245.

Mayer, L.I., Edreira, J.R.I., and Maddonni, G.A. 2014. Oil yield components of maize crops exposed to heat stress during early and late grain-filling stages. Crop Science 54:2236-2250. doi:10.2135/cropsci2013.11.0795.

Mazvimbakupa, F., Thembinkosi Modi, A., and Mabhaudhi, T. 2015. Seed quality and water use characteristics of maize landraces compared with selected commercial hybrids. Chilean Journal of Agricultural Research 75:13-20. doi.org/10.4067/S0718-58392015000100002.

Mi, N., Cai, F., Zhang, Y., Ji, R., Zhang, S., and Wang, Y. 2018. Differential responses of maize yield to drought at vegetative and reproductive stages. Plant, Soil and Environment 6(64):260-267.

Nascimento-Júnior, I., Moro, G.V., and Moro, F.V. 2018. Indirect selection of maize genotypes based on associations between root agronomic and anatomical characters. Chilean Journal of Agricultural Research 78:39-47. doi:10.4067/S0718-58392018000100039.

Official Gazette of the Republic of Serbia. 2006. National regulation on control of the seed production, the content and the method of keeping records on production of seedlings of agricultural crops and the form on the report on the production of mycelia of edible and medicinal fungi. Issue 2006/06. Official Gazette of the Republic of Serbia, Belgrade, Serbia.

Pommel, B., Mouraux, D., Cappellen, O., and Ledent, J.F. 2002. Influence of delayed emergence and canopy skips on the growth and development of maize plants: A plant scale approach with CERES maize. European Journal of Agronomy 16:263-277. doi:10.1016/S1161-0301(01)00130-7.

Rattalino Edreira, J.I., Budakli Carpici, E.B., Sammarro, D., and Otegui, M.E. 2011. Heat stress effects around flowering on kernel set of temperate and tropical maize hybrids. Field Crops Research 123:62-73. doi:10.1016/j.fcr.2011.04.015.

Sadras, V.O. 2007. Evolutionary aspects of the trade-off between seed size and number in crops. Field Crops Research 100:125-138.

Spitkó, T., Nagy, Z., Zsubori, Z.T., Halmos, G., Bányai, J., and Marton, L.C. 2014. Effect of drought on yield components of maize hybrids: Zea mays L. Maydica 59:161-169.

Styer, R.C., and Cantliffe, D.J. 1983. Relationship between environment during seed development and seed vigor of two endosperm mutant of corn. Journal of the American Society for Horticultural Science 108:717-720. 
Torres, G.X., Viana, A.P., Vieira, H.D., Rodrigues, D.L., and dos Santos, V.O. 2019. Contribution of seed traits to the genetic diversity of a segregating population of Passiflora spp. Chilean Journal of Agricultural Research 79:288-295. doi:10.4067/S0718-58392019000200288.

Wann, E.V. 1980. Seed vigor and respiration of maize kernels with different endosperm genotypes. Journal of the American Society for Horticultural Science 105:31-34.

Westoby, M., Jurado, E., and Leishman, M. 1992. Comparative evolutionary ecology of seed size. Journals Trends in Ecology and Evolution 7:368-372. doi:10.1016/0169-5347(92)90006-W.

Zhou, B., Yue, Y., Sun, X., Wang, X., Wang, Z., Ma, W., et al. 2016. Maize grain yield and dry matter production responses to variations in weather conditions. Agronomy Journal 108:196-204. doi:10.2134/agronj2015.0196. 